\title{
An Efficient Route to Well-Defined Macrocyclic Polymers via "Click" Cyclization
}

\author{
Boyd A. Laurent, Scott M. Grayson* \\ Department of Chemistry, Tulane University, New Orleans, LA 70118
}

\section{SUPPLEMENTARY DATA}

Acknowledgments: The authors would like to thank Prof. Karen Wooley, Dr. Chong Cheng, Kenya Powell, Brooke van Horn, Shrinivas Venkataraman, and David Germack, for assistance and helpful discussions, and Dr. Fong-Fu Hsu at the Washington University Medical School Mass Spectrometry Resource for assistance obtaining the MALDI-TOF MS data. Mass spectrometry services were provided by the Washington University Mass Spectrometry Resource with support from the NIH National Center for Research Resources (Grant No. P41RR0954)

Nomenclature: In order to simplify the identification of compounds, the following convention was applied: As a prefix, $l$-was assigned to linear polymers and $c$ - to cyclic polymers. The name consisted of PS, as an abbreviation for poly(styrene), followed by the approximate average molecular weight determined by MALDI-TOF MS. A suffix was added to identify the functionality at the terminal end of the polymer chain: $-\mathrm{Br}$, for the benzylic bromide, and $-\mathrm{N}_{3}$ for the benzylic azide.

Materials: All reagents were purchased from Aldrich and used without further purification, unless otherwise noted. All monomers were passed through a plug of neutral alumina to remove the stabilizers. All solvents were reagent grade and taken directly from the bottle without distillation or further purification.

Characterization: All ${ }^{1} \mathrm{H}$ NMR $(300 \mathrm{MHz})$ and ${ }^{13} \mathrm{C}$ NMR $(75 \mathrm{MHz})$ were obtained on a Varian Mercury $300 \mathrm{MHz}$ spectrometer (Palo Alto, CA), using the solvent signal for calibration. IR spectra were obtained using a Perkins-Elmer Spectrum BX Fouriertransform infrared (FTIR) spectrometer. Mass spectral data were acquired using an Applied Biosystems Voyager Elite matrix-assisted laser desorption time of flight mass (MALDI-TOF MS) spectrometer with delayed extraction using the linear positive ion mode. Dithranol was used as the matrix, and silver trifluoroacetate as the cation source, in a 50/5/2 Matrix/Ag+/polymer ration. The relaxation delay was set to $500 \mathrm{nsec}$, with an acceleration voltage of $18 \mathrm{kV}$, a grid voltage of $92 \%$, without guide wire, and low mass gate at 700 AMU. Size exclusion chromatography was carried out on a Waters model 1500 series pump (Milford, MA) with two-column series from Polymer Laboratories, Inc. consisting of PLgel $5 \mu \mathrm{m}$ Mixed C (300mm x $7.5 \mathrm{~mm})$ and PLgel $5 \mu \mathrm{m} 500$ A $(300 \mathrm{~mm}$ x $7.5 \mathrm{~mm}$ ) columns. The system was fitted with a Model 2414 differential refractometer detector and anhydrous tetrahydrofuran was used as the mobile phase $\left(1 \mathrm{~mL} \mathrm{~min}\right.$ min $^{-1}$ flow rate). The calculated molecular weight was based on calibration using linear polystyrene standards. Data was collected and processed using Precision Acquire software.

\section{Experimental Data:}

Polymerization of $\boldsymbol{l}$-PS4200-Br. A $100 \mathrm{ml}$ round bottomed flask containing $0.062 \mathrm{~g}$ (0.436mmol) $\mathrm{CuBr}, 0.005 \mathrm{~g}(0.022 \mathrm{mmol}) \mathrm{CuBr}_{2}, 0.098 \mathrm{~g}(0.567 \mathrm{mmol})$ PMDETA, and $2.727 \mathrm{~g}(26.183 \mathrm{mmol})$ styrene was degassed using 2 freeze/pump/thaw cycles. After warming to room temperature, $0.089 \mathrm{~g}(0.436 \mathrm{mmol})$ of the initiator was added via syringe. The reaction mixture was placed in a preheated $75{ }^{\circ} \mathrm{C}$ oil bath and allowed to stir under nitrogen for four hours. The reaction mixture was then cooled to room temperature and purified by extraction from water into dichloromethane followed by precipitation into methanol to yield the polymer as a white solid (yield 87\%). ${ }^{1} \mathrm{H}$ NMR 
$\left(\mathrm{CDCl}_{3}, \delta\right.$, ppm, TMS) 0.8-1.1 (br, 6), 1.2-2.5 (br, 92), 3.7-4.2 (br, 2), 4.3-4.6 (br, 1), 6.2$7.4\left(\right.$ br, 157) calcd. $M_{n}=3430$. MS (MALDI-TOF): $(\mathrm{m} / \mathrm{z}), \mathrm{M}_{\mathrm{n}}=4100$, PDI $=1.07$. SEC: $\quad M_{n}=4260$, PDI $=1.16 . \quad$ IR: 3275, 3033, 3025, 2950, 2923, 2849, 1940, 1869, $1801,1733,1599,1492,1452,1364,1122,1066,907,757,658 \mathrm{~cm}^{-1}$.

Preparation of $\boldsymbol{l}$-PS4200-N $-\mathbf{N}_{3}$. To a $100 \mathrm{ml}$ round bottomed flask was added $0.5 \mathrm{~g}$ $(0.111 \mathrm{mmol}) l$-PS-Br. The polymer was then dissolved into $10 \mathrm{ml} \mathrm{DMF}$ and $0.036 \mathrm{~g}$ $(0.555 \mathrm{mmol})$ sodium azide was added as a solid. The solution was allowed to stir overnight at room temperature before purification by precipitation into methanol to give a white solid (yield 83\%). ${ }^{1} \mathrm{H}$ NMR $\left(\mathrm{CDCl}_{3}, \delta\right.$, ppm, TMS) 0.9-1.1 (b, 6), 1.3-2.3 (b, 105), 3.8-4.2 (b, 3), 6.4-7.4 (b, 171) calcd. $\mathrm{M}_{\mathrm{n}}=3850$. MS (MALDI-TOF): $(\mathrm{m} / \mathrm{z}), \mathrm{M}_{\mathrm{n}}=4200$ PDI $=1.06 . \quad$ SEC: $M_{n}=4850$, PDI $=1.13 . \quad$ IR: 3288, 3034, 3025, 2921, 2848, 2093, $1942,1867,1801,1733,1600,1492,1451,1264,1026,739,697 \mathrm{~cm}^{-1}$.

Cyclization of $\boldsymbol{c}$-PS4200. To a $250 \mathrm{ml}$ round bottomed flask was added $115 \mathrm{ml}$ of DMF which was degassed using 2 freeze/pump/ thaw cycles. $0.159 \mathrm{~g}(1.111 \mathrm{mmol}) \mathrm{CuBr}$ and $0.344 \mathrm{~g}(2.2 \mathrm{mmol})$ bipy were added to the frozen DMF. The flask was then resealed, evacuated, and refilled with $\mathrm{N}_{2}$. A separate flask containing $0.05 \mathrm{~g}(0.011 \mathrm{mmol}) l$-PS-N 3 dissolved in $5 \mathrm{ml}$ DMF was degassed through 2 freeze/pump/thaw cycles. This solution was then added to the $\mathrm{CuBr} / \mathrm{bpy}$ reaction solution at $120{ }^{\circ} \mathrm{C}$ via a syringe pump at a rate of $0.2 \mathrm{ml} / \mathrm{hr}(0.4 \mu \mathrm{mol} / \mathrm{hr})$. Once the polymer was finished adding to the catalyst solution, the reaction was allowed to proceed at $120{ }^{\circ} \mathrm{C}$ for an additional $1 \mathrm{hr}$ before cooling to room temperature followed by extraction into DCM. The organic layer was washed multiple time with saturated $\mathrm{NaHSO}_{4}$ solutions, dried over $\mathrm{MgSO}_{4}$, and concentrated in vасио. The crude polymer was then precipitated in methanol to give a white solid (yield 80\%). ${ }^{1} \mathrm{H}$ NMR $\left(\mathrm{CDCl}_{3}, \delta\right.$, ppm, TMS) 0.8-1.1 (b, 6), 1.3-2.3 (b, 92), 4.3-4.7 (b, 2), 4.95.2 (b, 1), 6.3-7.4 (b, 146) calcd. $\mathrm{M}_{\mathrm{n}}=3330$. MS (MALDI-TOF): $(\mathrm{m} / \mathrm{z}), \mathrm{M}_{\mathrm{n}}=4170$, PDI $=1.04 . \quad$ SEC: $\mathrm{M}_{\mathrm{n}}=3240, \mathrm{PDI}=1.28 . \quad$ IR: $3628,3025,2922,2849,1939,1866$, $1794,1724,1599,1492,1451,1066,1027,753,698 \mathrm{~cm}^{-1}$.

Polymerization of $\boldsymbol{l}$-PS2200-Br. A $100 \mathrm{ml}$ round bottomed containing $0.062 \mathrm{~g}$ $(0.436 \mathrm{mmol}) \mathrm{CuBr}, 0.005 \mathrm{~g}(0.022 \mathrm{mmol}) \mathrm{CuBr}_{2}, 0.098 \mathrm{~g}(0.567 \mathrm{mmol})$ PMDETA, and $2.727 \mathrm{~g}(26.183 \mathrm{mmol})$ styrene was degassed using 2 freeze/pump/thaw cycles. After warming to room temperature, $0.089 \mathrm{~g}(0.436 \mathrm{mmol})$ of the initiator was added via syringe. The reaction mixture was placed in a preheated $75{ }^{\circ} \mathrm{C}$ oil bath and allowed to stir under nitrogen for two hours. The reaction mixture was then cooled to room temperature and purified by extraction from water into dichloromethane followed by precipitation into methanol to yield the polymer as a white solid (yield $45 \%$ ). ${ }^{1} \mathrm{H}$ NMR $\left(\mathrm{CDCl}_{3}, \delta\right.$, ppm, TMS) 0.8-1.1, (br, 6), 1.3-2.5 (br, 43), 3.8-4.2 (br, 2), 4.4-4.7 (br, 1), 6.4-7.4 (br, 75) calcd. $M_{n}=1760$. MS (MALDI-TOF): $(\mathrm{m} / \mathrm{z}), \mathrm{M}_{\mathrm{n}}=2140, \mathrm{PDI}=1.08$. SEC: $\quad M_{n}=1390$, PDI $=1.19 . \quad$ IR: 3283, 3031, 3024, 2922, 2847, 1937, 1866, 1795, $1731,1600,1491,1452,1121,1026,755,698 \mathrm{~cm}^{-1}$.

Preparation of $\boldsymbol{l}$-PS2200-N $\mathbf{N}_{3}$. To a $100 \mathrm{ml}$ round bottomed flask was added $0.4 \mathrm{~g}$ $(0.235 \mathrm{mmol}) l$-PS-Br. The polymer was then dissolved into $8 \mathrm{ml} \mathrm{DMF}$ and $.076 \mathrm{~g}$ $(1.176 \mathrm{mmol})$ sodium azide was added as a solid. The solution was allowed to stir overnight at room temperature before purification by precipitation into methanol to give a white solid (yield 68\%). ${ }^{\mathrm{H}} \mathrm{NMR}\left(\mathrm{CDCl}_{3}, \delta\right.$, ppm, TMS) 0.9-1.1 (b, 6), 1.3-2.4 (b, 48), 3.7-4.2 (b, 3), 6.3-7.4 (b, 80) calcd. $\mathrm{M}_{\mathrm{n}}=1870$. MS (MALDI-TOF): (m/z), $\mathrm{M}_{\mathrm{n}}=2160$ PDI $=1.09$. SEC: $\mathbf{M}_{\mathrm{n}}=2050, \mathrm{PDI}=1.16$. IR: 3290, 3035, 3024, 2917, 2848, 2091, $1940,1865,1797,1730,1600,1491,1452,1264,1121,1027,737,697 \mathrm{~cm}^{-1}$.

Cyclization of $\boldsymbol{c}$-PS2200. To a $250 \mathrm{ml}$ round bottomed flask was added $110 \mathrm{ml}$ of DMF which was degassed using 2 freeze/pump/ thaw cycles. $0.159 \mathrm{~g}(1.111 \mathrm{mmol}) \mathrm{CuBr}$ and $0.344 \mathrm{~g}(2.2 \mathrm{mmol})$ bipy were added to the frozen DMF. The flask was then resealed, evacuated, and refilled with $\mathrm{N}_{2}$. A separate flask containing $0.037 \mathrm{~g}(0.022 \mathrm{mmol}) l-\mathrm{PS}-\mathrm{N}_{3}$ dissolved in $10 \mathrm{ml}$ DMF was degassed through 2 freeze/pump/thaw cycles. This solution was then added to the $\mathrm{CuBr} / \mathrm{bpy}$ reaction solution at $120^{\circ} \mathrm{C}$ via syringe pump at a rate of 
$0.2 \mathrm{ml} / \mathrm{hr}(0.4 \mu \mathrm{mol} / \mathrm{hr})$. Once the polymer was finished adding to the catalyst solution, the reaction was allowed to proceed at $120{ }^{\circ} \mathrm{C}$ for an additional $7 \mathrm{hrs}$. before cooling to room temperature followed by extraction into DCM. The organic layer was washed multiple times with saturated $\mathrm{NaHSO}_{4}$ solutions, dried over $\mathrm{MgSO}_{4}$, and concentrated in vacuo. The crude polymer was then precipitated into methanol to give a white solid (yield 92\%). ${ }^{1} \mathrm{H}$ NMR (CDCl $3, \delta$, ppm, TMS) 0.8-1.1, (b, 6), 1.2-2.4, (b, 47), 4.4-4.9 (b, 2), 4.9-5.2, (b, $1 \mathrm{H})$, 6.3-7.4, $(\mathrm{b}, 77)$ calcd. $\mathrm{M}_{\mathrm{n}}=1810$. MS (MALDI-TOF): $(\mathrm{m} / \mathrm{z}), \mathrm{M}_{\mathrm{n}}=2160, \mathrm{PDI}=$ 1.08. SEC: $\mathrm{M}_{\mathrm{n}}=990$, PDI = 1.19. IR: 3629, 3057, 3025, 2922, 2850, 1941, 1864, 1801, $1725,1600,1492,451,1126,1068,1027,758,698 \mathrm{~cm}^{-1}$.

Polymerization of $\boldsymbol{l}$-AcOPS2500-Br. A $100 \mathrm{ml}$ round bottomed containing $0.048 \mathrm{~g}$ $(0.335 \mathrm{mmol}) \mathrm{CuBr}, 0.004 \mathrm{~g}(0.017 \mathrm{mmol}) \mathrm{CuBr}_{2}, 0.157 \mathrm{~g}(1.005 \mathrm{mmol})$ bipy, and $2.12 \mathrm{~g}$ (13.071 mmol) 4-acetoxystyrene was degassed using 2 freeze/pump/thaw cycles. After warming to room temperature, $0.068 \mathrm{~g}(0.335 \mathrm{mmol})$ of the initiator was added via syringe. The reaction mixture was placed in a preheated $75{ }^{\circ} \mathrm{C}$ oil bath and allowed to stir under nitrogen for three hours. The reaction mixture was then cooled to room temperature and purified by extraction from water into dichloromethane followed by precipitation into a methanol/ water (3:1) to give the polymer as a white solid (yield $75 \%$ ). ${ }^{1} \mathrm{H}$ NMR $\left(\mathrm{CDCl}_{3}, \delta\right.$, ppm, TMS) 0.8-1.1, (br, 6), 1.3-2.6 (br, 105), 3.8-4.2 (br, 2), 4.3-4.6 (br, 1), 6.2-7.2 (br, 70) calcd. $\mathrm{M}_{\mathrm{n}}=2800 \mathrm{MS}$ (MALDI-TOF): (m/z), $\mathrm{M}_{\mathrm{n}}=2460$, PDI $=1.09 . \quad$ SEC: $\quad \mathrm{M}_{\mathrm{n}}=2740, \mathrm{PDI}=1.19 . \quad \mathrm{IR}: 3468,3271,3031,2921,2849,2120$, $1998,1893,1759,1602,1505,1420,1368,1193,1016,910,846,733 \mathrm{~cm}^{-1}$.

Preparation of $\boldsymbol{l}$ - AcOPS2500-N . To a $100 \mathrm{ml}$ round bottomed flask was added $.845 \mathrm{~g}$ $(.282 \mathrm{mmol}) l$-AcOPS-Br. The polymer was then dissolved into $6 \mathrm{ml} \mathrm{DMF}$ and $.092 \mathrm{~g}$ (1.408mmol) sodium azide was added as a solid. The solution was allowed to stir overnight at room temperature before purification by precipitation into methanol/ water (3:1) to give a white solid (yield 92\%). ${ }^{1} \mathrm{H} \mathrm{NMR}\left(\mathrm{CDCl}_{3}, \delta\right.$, ppm, TMS) 0.9-1.1 (b, 6), 1.2-2.4 (b, 113), 3.8-4.2 (b, 3), 6.2-7.1 (b, 78) calcd. $\mathrm{M}_{\mathrm{n}}=2960$. MS (MALDI-TOF): $(\mathrm{m} / \mathrm{z}), \quad \mathrm{M}_{\mathrm{n}}=2940$ PDI $=1.09 . \quad$ SEC: $\mathrm{M}_{\mathrm{n}}=2880$, PDI $=1.19 . \quad$ IR: $3486,3277,3032$, 2921, 2849, 2096, 1745, 1602, 1501, 1421, 1365, 1165, 1012, 909, 846, $733 \mathrm{~cm}^{-1}$.

Cyclization of $c$ - AcOPS2500. To a $250 \mathrm{ml}$ round bottomed flask was added $110 \mathrm{ml}$ of DMF which was degassed using 2 freeze/pump/ thaw cycles. $0.159 \mathrm{~g}(1.111 \mathrm{mmol}) \mathrm{CuBr}$ and $0.344 \mathrm{~g}(2.2 \mathrm{mmol})$ bipy were added to the frozen DMF. The flask was then resealed, evacuated, and refilled with $\mathrm{N}_{2}$. A separate flask containing $0.044 \mathrm{~g}(0.018 \mathrm{mmol}) l$-PS-N 3 dissolved in $8 \mathrm{ml}$ DMF was degassed through 2 freeze/pump/thaw cycles. This solution was then added to the preheated $\mathrm{CuBr} / \mathrm{bpy}$ reaction solution at $120{ }^{\circ} \mathrm{C}$ via syringe pump at a rate of $0.2 \mathrm{ml} / \mathrm{hr}(0.4 \mu \mathrm{mol} / \mathrm{hr})$. Once the polymer was finished adding to the catalyst solution, the reaction was allowed to proceed at $120{ }^{\circ} \mathrm{C}$ for an additional $7 \mathrm{hrs}$. before cooling to room temperature followed by extraction into DCM. The organic layer was washed multiple times with saturated $\mathrm{NaHSO}_{4}$ solutions, dried over $\mathrm{MgSO}_{4}$, and concentrated in vacuo. The crude polymer was then precipitated into methanol/ water (3:1) to give a white solid (yield 64\%). ${ }^{1} \mathrm{H}$ NMR $\left(\mathrm{CDCl}_{3}, \delta\right.$, ppm, TMS) 0.7-1.1 (b, 6), 1.1-2.5 (b, 92), 4.3-4.8 (b, 2), 4.8-5.3 (b, 1), 6.2-7.2 (b, 58) calcd. $\mathrm{M}_{\mathrm{n}}=2470$. MS $\left(\right.$ MALDI-TOF): $(\mathrm{m} / \mathrm{z}), \mathrm{M}_{\mathrm{n}}=2830, \mathrm{PDI}=1.08 . \quad \mathrm{SEC}: \mathrm{M}_{\mathrm{n}}=2540, \mathrm{PDI}=1.24 . \mathrm{IR}: 3445$, 3031, 2937, 2919, 2848, 2097, 2002, 1897, 1759, 1603, 1502, 1379, 1366, 1193, 1094, $1014,910,798,729 \mathrm{~cm}^{-1}$. 
Figure S1: Overlay of SEC traces of $l-\mathrm{PS} 2200-\mathrm{N}_{3}$ (in black) and $c$-PS2200 (in grey).

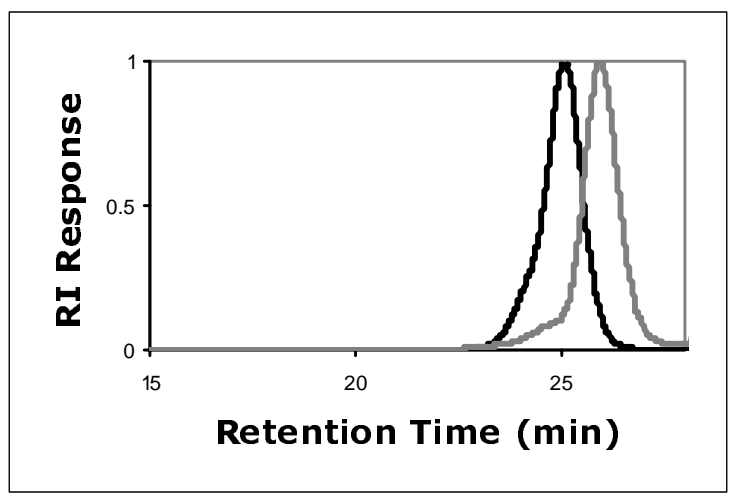

Figure S2: Full MALDI TOF mass spectrum of cyclized $c$-PS2200.

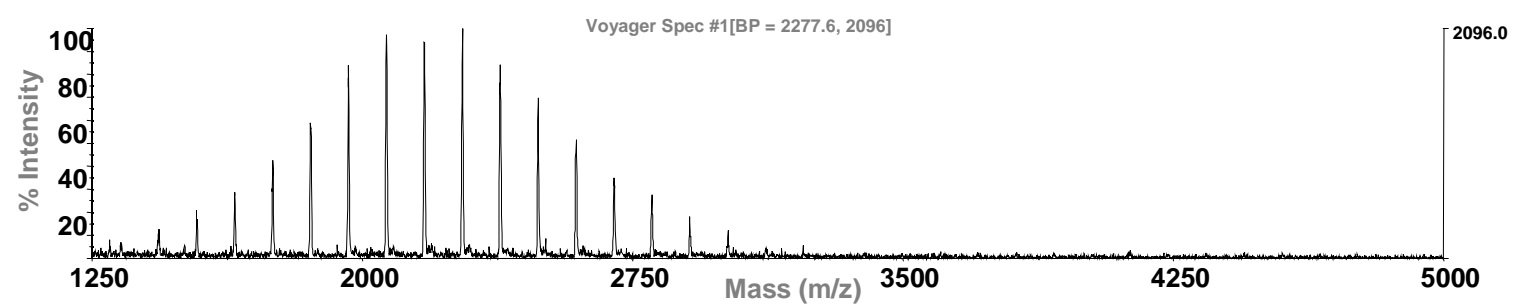

Figure S3: Full MALDI TOF mass spectrum of cyclized $c$-PS4200.

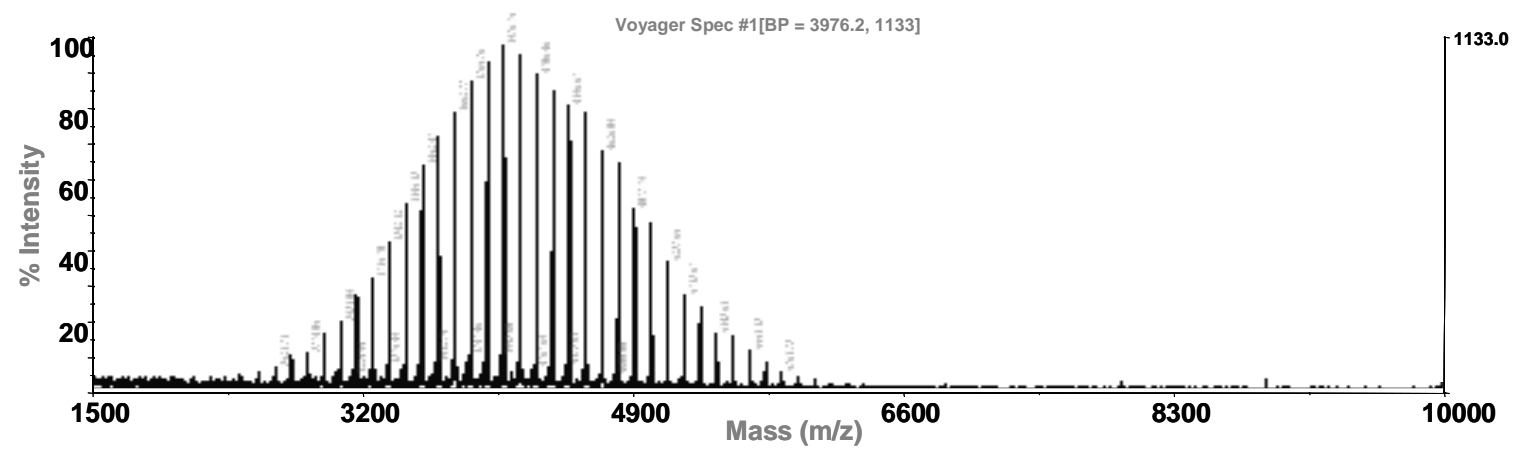


Figure S4: Minor species present in MALDI-TOF MS of the a) azide terminated polymer, $l$-PS4200- $\mathrm{N}_{3}$ exhibiting the characteristic $\left[\mathrm{M}-\mathrm{N}_{2}\right]^{+}$and benzylic $\left[\mathrm{M}-\mathrm{N}_{3}\right]^{+}$peaks and b) the triazole linked cyclic polymer, $c$-PS4200, exhibiting the characteristic $\left[\mathrm{M}-\mathrm{N}_{2}\right]^{+}$ peak.
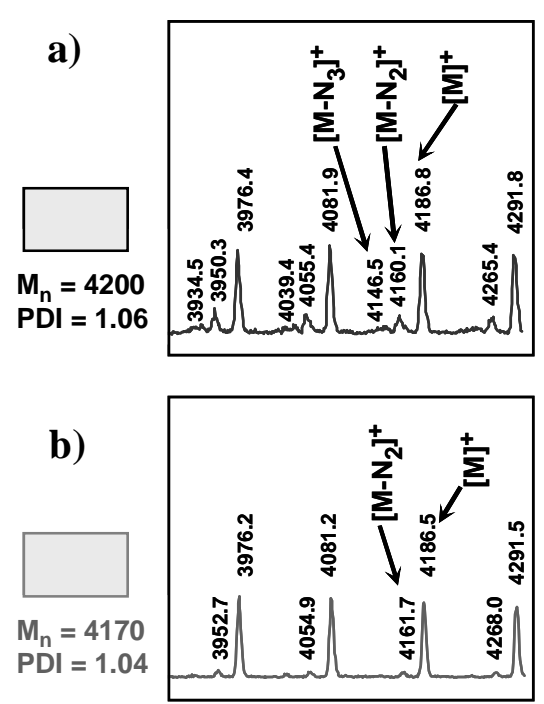